\title{
Perspectives of neurosurgery for psychiatric disorders
}

\author{
Marcelo B de Sousa and Paulo SB de Abreu
}

Department of Psychiatry, Hospital de Clínicas de Porto Alegre, Brazil

The neurosurgical treatment of severe psychiatric disorders has a history that goes back to antiquity [1]. The term "psychosurgery" was created by Egas Munis in the middle of the 20th century, when this procedure became popular [2].

Due to the abuse of psychosurgery in the past, often used indiscriminately and contraindicated (such as performing a lobotomy in a troubled child), it generated absurd rates of morbidity and mortality, causing a strong negative reaction in society [3]. In addition, from the emergence of effective psychotropic drugs, neurosurgical treatment for psychiatric disorders has been practically abandoned for a considerable period [1]. Currently, the procedures, when allowed, are under strict control of the committees of Neurosurgery for psychiatric diseases of referral hospitals and submitted to strict legislation in most countries [4].

In Brazil, for example, the legislation requires that all psychosurgeries can only occur with the authorization of the local medical council. This generally is a very time-consuming process, causing difficulty in assisting patients who need the procedure.

Of the ten most disabling diseases in the world, five belong to psychiatry: depression, alcoholism, bipolar disorder, schizophrenia and obsessive-compulsive disorder (OCD) [5]. Unfortunately, no matter how good the quality of care is, there is a group of very serious patients who are refractory to various treatment regimens. For these, the resource of the neurosurgical treatment fits [1].

The psychosurgery has been used primarily in refractory cases of OCD, schizophrenia, depression and aggressive behaviour. Although there are also reports of approaches to addiction disorders, anorexia, among others [3].

The evolution of treatments from grotesque and low discriminated lesions such as lobotomies to stereotactic approaches allowed a better selection of targets of interest with a much lower incidence of adverse effects [6].

In this way, capsulotomy, cingulotomy, subcaudal tractomy and limbic leucotomy are recommended as more usual and adequate approaches. The choice of the site of the brain to be approached is related to the symptomatology of the patient and to the experience of each center with a certain surgical technique [6].

Unfortunately, we have very few RCTs in this area, with the case series of each center predominating. Thus, the level of scientific evidence for the choice of each surgical target for a given disease is limited [7]. On the other hand, with better knowledge of the brain circuits through the advancement of imaging tests, in particular the tractography, it is already possible to carry out studies that allow for predictive results of response, which will make increasingly more based the choices of approach already in the near future from the customization of treatments $[8,9]$.
Four modalities of psychosurgery are currently available: traditional radiofrequency surgery, DBS implantation, gamma knife radiosurgery and ultrasound surgery, the latter being still very restricted $[10,11]$. Each of these modalities presents advantages and disadvantages with respect to reversibility, onset of action, need for follow-up after the procedure and cost [10].

The DBS arose from the treatment of patients with movement disorders refractory to the usual drug therapy, allowing for very satisfactory improvements when properly indicated. These promising results motivated researchers to use this feature in psychiatric patients, especially with OCD and depression, which were also encouraged at first, but were not as effective after the publication of RCTs [12-14].

In fact, perhaps the greatest merit of the use of DBS in psychiatry, because it is a reversible and less stigmatizing procedure, has been to rekindle the interest of researchers and of society as a whole in the subject. Regrettably, we still pay the price for the mistakes of the past, which explains the control that currently exists on these approaches. Perhaps a neurosurgeon will never have as much autonomy to perform a psychosurgery as he has to operate a brain tumour. However, in the future, the "clock pendulum" may go down the middle, and legislation will be less bureaucratic, allowing this important treatment to be offered to a largest number of severely ill individuals.

We also hope that other forms of radiotherapy other than the gamma knife can be used to treat refractory psychiatric patients. Linear accelerator radiotherapy (LINAC), for instance, is already used to perform thalamotomies in patients with a contraindication to DBS or radiofrequency [15]. Because LINAC is much more available and has no further limitations of gamma knife devices, we believe that there is a very promising space in its use in psychosurgery [16].

\section{References}

1. Staudt MD, Herring EZ, Gao K, Miller JP, et al. (2019) Evolution in the Treatment of Psychiatric Disorders: From Psychosurgery to Psychopharmacology to Neuromodulation. Front Neurosci 13: 108. [Crossref]

2. Mashour GA, Walker EE, Martuza RL (2005) Psychosurgery: past, present, and future. Brain Res Brain Res Rev 48: 409-419. [Crossref]

3. Robison RA, Taghva A, Liu CY, Apuzzo ML (2012) Surgery of the Mind, Mood, and Conscious State: An Idea in Evolution. World Neurosurg 77: 662-686. [Crossref]

4. Lipsman N, Bernstein M, Lozano AM (2010) Criteria for the ethical conduct of psychiatric neurosurgery clinical trials. Neurosurg Focus 29: E9. [Crossref]

${ }^{\star}$ Correspondence to: Marcelo Basso de Sousa, Department of Psychiatry, Hospital de Clínicas de Porto Alegre, Rua Ramiro Barcelos, 2350, $4^{\circ}$ andar. Porto Alegre, Brazil, E-mail: basso.psiq@gmail.com

Received: April 02, 2019; Accepted: April 12, 2019; Published: April 15, 2019 
5. Murray CJL, Lopez AD (1996) The Global Burden of Disease:A Comprehensive Assessment of Mortality and Disability From Diseases, Injuries, and Risk Factors in 1990 and Projected to 2020. Cambridge: Harvard University Press.

6. Patel SR, Aronson JP, Sheth SA, Eskandar EN (2013) Lesion procedures in psychiatric neurosurgery. World Neurosurg 80: S31. [Crossref]

7. Lopes AC, Greenberg BD, Canteras MM, Batistuzzo MC, Hoexter MQ, et al. (2014) Gamma ventral capsulotomy for obsessive-compulsive disorder: a randomized clinical trial. JAMA Psychiatry 71: 1066-1076. [Crossref]

8. Banks GP, Mikell CB, Youngerman BE, Henriques B, Kelly KM, et al. (2015) Neuroanatomical characteristics associated with response to dorsal anterior cingulotomy for obsessive-compulsive disorder. JAMA Psychiatry 72: 127-135. [Crossref]

9. Yin D, Zhang C, Lv Q, Chen X, Zeljic K, et al. (2018) Dissociable Frontostriatal Connectivity: Mechanism and Predictor of the Clinical Efficacy of Capsulotomy in Obsessive-Compulsive Disorder. Biol Psychiatry 84: 926-936. [Crossref]

10. Müller S, Riedmüller R, van Oosterhout A (2015) Rivaling paradigms in psychiatric neurosurgery: adjustability versus quick fix versus minimal-invasiveness. Front Integr Neurosci 9: 27. [Crossref]
11. Quadri SA, Waqas M, Khan I, Khan MA, Suriya SS, et al. (2018) High-intensity focused ultrasound: past, present, and future in neurosurgery. Neurosurg Focus 44 E16. [Crossref]

12. Pepper J, Hariz M, Zrinzo L (2015) Deep brain stimulation versus anterior capsulotomy for obsessive-compulsive disorder: a review of the literature. J Neurosurg 122: 10281037. [Crossref]

13. Holtzheimer PE, Husain MM, Lisanby SH, Taylor SF, Whitworth LA, et al. (2017) Subcallosal cingulate deep brain stimulation for treatment-resistant depression: a multisite, randomised, sham-controlled trial. Lancet Psychiatry 4: 839-849. [Crossref]

14. Agarwal P, Sarris CE, Herschman Y, Agarwal N, Mammis A (2016) Schizophrenia and neurosurgery: A dark past with hope of a brighter future. J Clin Neurosci 34: 53-58. [Crossref]

15. Frighetto L1, De Salles A, Wallace R, Ford J, Selch M, et al. (2004) Linear accelerator thalamotomy. Surg Neurol 62: 106-113. [Crossref]

16. Schwartz M (1998) Stereotactic radiosurgery: comparing different technologies. CMAJ 158: 625-628. [Crossref]

Copyright: $\left({ }^{2} 2019\right.$ de Sousa MB. This is an open-access article distributed under the terms of the Creative Commons Attribution License, which permits unrestricted use, distribution, and reproduction in any medium, provided the original author and source are credited. 